\title{
Qualidade de Vida: Percepção de Crianças e Adolescentes Estomizados e seus Pais e/ou Responsáveis*
}

\author{
Quality of Life: Perception of Ostomized Children \\ and Adolescents and their Parents and/or Guardians
}

\author{
Calidad de Vida: la Percepción de los Niños y Adolescentes \\ con Estomía y sus Padres y/o Tutores
}

Sandra de Nazaré Costa Monteiro', Ivone Kamada², Ana Lúcia da Silva

*Dissertação de Mestrado apresentada ao Programa de Pós-graduação em Enfermagem da Faculdade de Ciências da Saúde da Universidade de Brasília (UnB), em 29/11/2013.

A estomia é uma situação que atinge pessoas de todas as faixas etárias. Crianças e adolescentes podem adquirir estomas urinários ou gastrintestinais por diversas causas, entre as mais frequentes estão as anomalias congênitas e os traumas ocorridos durante o desenvolvimento. A qualidade de vida é um conceito complexo, de caráter subjetivo e multidimensional, que engloba vários aspectos da vida e que vem ganhando o interesse dos estudiosos. De forma geral, a qualidade de vida de crianças e adolescentes tem sido avaliada a partir dos relatos de adultos, com uma escassez de instrumentos destinados a essa mensuração, o que dificulta a análise por tais sujeitos. Na área de saúde, existe um debate acerca de qual seria o respondente adequado para se avaliar a qualidade de vida da criança e do adolescente, considerando-se importante analisar a correlação entre as respostas da criança, do adolescente e de seus respectivos pais e/ou responsáveis. O objetivo de tal estudo foi conhecer a qualidade de vida de crianças e adolescentes estomizados e seus respectivos pais e/ou responsáveis, a partir de suas próprias percepções. Para tanto, realizou-se uma pesquisa com abordagem quantitativa, transversal exploratória e descritiva com a aplicação de um instrumento de qualidade de vida, que inclui três grandes domínios: mental, social e físico. Os dados foram obtidos por meio de prontuários e entrevista com autorrelato, e posteriormente transformados em análises com o software SPSS 20.0. Foram estudados 20 crianças e adolescentes estomizados entre 8 e 18 anos, e 20 pais e/ou responsáveis. Para a coleta de dados, utilizou-se um questionário sociodemográfico e, para a avaliação da qualidade de vida, aplicou-se a versão brasileira denominada "Módulo Genérico DISABKIDS ${ }^{\circledR}$ para crianças e adolescentes brasileiros com condições crônicas (MGDC-37)". Houve uma boa consistência nas respostas dos grupos. Foram encontradas diferenças estatisticamente significativas em todas as dimensões e domínios. Os estomizados perceberam-se independentes, emocionalmente afetados pela condição de saúde, excluídos do convívio social e com difícil aceitação do tratamento pelo uso do equipamento coletor. Já seus pais e/ou responsáveis notaram a dependência dos filhos e não perceberam a exclusão social que promoveram a partir da superproteção. Houve uma importante correlação entre grupos na dimensão exclusão social, pois os estomizados perceberam-se extremamente excluídos dos espaços de convívio social. O DISABKIDS ${ }^{\circledR}$ MGDC-37 apresenta boa sensibilidade para avaliar a qualidade de vida de crianças e adolescentes a partir de suas próprias percepções, além de demonstrar que esses indivíduos são capazes de fornecerem informações sobre si mesmos e, consequentemente, de sua vida. Esses dados são fundamentais para subsidiar a prática clínica profissional e contribuir com a elaboração de planos assistenciais e protocolos de atendimento específicos para essa população.

DESCRITORES: Estomaterapia. Estomia. Criança. Adolescente. Qualidade de Vida. Pais.

\footnotetext{
'Enfermeira; Especialista em Estomaterapia; Mestre em Enfermagem pela Universidade de Brasília (UnB): Docente da Escola Superior de Ciências da Saúde de Enfermagem - Brasília (DF), Brasil. Endereço para correspondência: SQS 206 - bloco I - apartamento 204 - CEP: $70252-090$ - Brasília (DF), Brasil - E-mail: sncmonteiro@yahoo.com.br

2Enfermeira; Docente; Doutora em Enfermagem pelo Departamento de Enfermagem da UnB - Brasília (DF), Brasil.

${ }^{3}$ Enfermeira Estomaterapeuta; Docente; Doutora em Enfermagem pelo Departamento de Enfermagem da UnB - Brasília (DF), Brasil.

Artigo recebido em: 05/04/2015 - Aceito para publicação em: 14/10/2015
} 